\title{
Antioxidant and antibacterial activities of polyphenolic compounds from bitter cumin (Cuminum nigrum $\mathrm{L}$.)
}

\author{
V. Ani • M. C. Varadaraj · K. Akhilender Naidu
}

Published online: 1 August 2006

(C) Springer-Verlag 2006

\section{Eur Food Res Technol (2006) s00217-006-0295-z}

The botanical name of bitter cumin has been wrongly reported as Cuminum nigrum $\mathrm{L}$. The botanical name of bitter cumin or black cumin is identified and authenticated as Centratherum anthelminticum (Willd.) Kuntz. The readers may kindly note that the reported antioxidant and antibacterial activities of polyphenolic compounds are from black/bitter cumin Centratherum anthelminticum (Willd.) Kuntz and not from Cuminum nigrum $\mathrm{L}$.

Centratherum anthelminticum (Willd.) belongs to the Compositae family. It is black in colour and has a bitter taste. It is an important medicinal plant used in local indigenous medicine as febrifugal, alterative, anthelmintic, antiphlegmatic, diuretic and digestive stimulant. It should be noted that there is lot of confusion with regard to black cumin. Nigella sativa (Ranunculaceae), Bunium persicum Boiss (Umbelliferae) and Centratherum anthelminticum Willd. (Compositae) are called as black cumin in India even though they belong to different species.

The online version of the original article can be found at http:// dx.doi.org/10.1007/s00217-006-0295-z

V. Ani $\cdot$ K. A. Naidu $(\bowtie)$

Biochemistry and Nutrition, Central Food Technological

Research Institute,

Mysore 570 020, India

e-mail:kanaidu@mailcity.com

Fax: +91-821-2517233

M. C. Varadaraj

Human Resource Development, Central Food Technological

Research Institute,

Mysore 570 020, India 